Article for the Journal of Illustration Vol. 2.2

\title{
Finnegans Wake: Readings Through Drawing
}

Clinton Cahill

Manchester Metropolitan University

Finnegans Wake is an extraordinary object but it struggles to be a book. It struggles against the constraints of the book form. As if James Joyce wanted to so overloaded the currents of literature form that he caused language itself to break its bonds and overflow its banks. The book wants to be something else. In its radical reconsideration of linear text, strategies of reiteration, foliation, patterning, typographic and paratextual experimentation, Finnegans Wake might be considered to move towards the condition of visual rather than purely literary image. Purportedly it ends in the middle of its first sentence, or begins in the midst of its last - but actually cannot, because it's a book. Its physical fact denies the ideal cycle it desires. The reader is flung blinking into the daylight of 'Paris 1939' and must arc through endpapers, covers, para-textual stuff and the real world to get back to the beginning. And then work to re-enter the Wake, again. The Wake re-configures categorical divisions between sleep and death, dream and history, past, present, future, body and landscape. The book's what, where, when and who in are indeterminate and mutable. On the bigger scale it seeks to bring together its own opposite ends and to square the circle. This desire to bring opposites together, often in unmitigated collision runs right through the text on macro and micro scales. (Joyce 1939).

Some of the extensive discourse generated about Finnegans Wake is undertaken through visual imagery. It is this broad category of responsiveness that I am interested in. My intention is to explore the possibility of a materially engaged reading practice that might depict and possibly augment an encounter with Joyce's last and most extraordinary book.

Increased interest in the visuality and the visual adaptation of Joyce's oeuvre has been advanced by work such as Joyce's Book of the Dark (Bishop 1986), with its analysis of the ocularity of the the Wake's dreamer, and critical survey of Joyce's impact on visual culture, Joyce in Art: Visual Art Inspired by James Joyce (Hayes 2004). The recent success of Dotter of Her Father's Eyes (Mary and Bryan Talbot 2012) and Robert Berry's long-term 'Ulysses Seen' project, have also helped to more firmly validate visual readings of Joyce through the popular graphic novel and comic strip format. However, responses to Finnegans Wake in art and design have tended to concentrate on textual explication or the influence of the book, not on representing the peculiar experience of reading it. My practice-based research is concerned with a form of graphic reading that responds to 
Joyce's 'nightbook' as both a physical and a literary object. This is intended to be a distinctive examination of the Wake's form and content, and of the affective experience of the reading act itself. Two associated propositional views underpin my approach:

That Finnegans Wake is an object made of words but one that possesses some of the operational conditions of an image; a modulated surface that utilizing and depicting surface tensions in language. It does this in a way that departs from the linear syntax associated with conventional expectations of the reading process. One implication of this, almost counter intuitive to the reputation of the book, is that Finnegans Wake may be peculiarly amenable to visual adaptation.

That Finnegans Wake has a particular capacity to be a generative meta-tool for graphic practice. It offers opportunities for exploring complex effects between text and image, and is an object through which illustrational drawing itself can become a mode of reading that renders Barthesian pleasure explicitly (Barthes 1975).

The place occupied by Finnegans Wake in the canon of western literature might make it seem an odd text for illustrative interpretation or adaptation. However, my reading experience and the book's persistently peripheral but symbolically central position as a hugely affective yet relatively sparsely work, lead me to regard it as an appropriate object through which to investigate the interaction of literary text and visual imagination.

The Wake is difficult to summarize, although many pithy descriptions have been offered - 'a book of the night', a 'hypermachinic Engine'. To Anthony Burgess it was 'A novel about an innkeeper who lives, with his wife Ann, his children Izzy and Kevin and Jerry, and the cleaning woman Kate and the barman Sackerson, in Chapelizod, just outside Dublin' but also 'as close to a work of nature as any artist ever got - massive, baffling, serving nothing but itself, suggesting a meaning but never quite yielding anything but a fraction of it, and yet (like a tree) desperately simple' (Burgess 1966); according to a reviewer in John O'London's Weekly it was 'that tremendous comic nightmare, that fabulous vivisection of language'.

I use drawing as a way of exploring my reading of Finnegans Wake. I am interested in how some readings of this text, including my own, are image experiences. Joyce's work has a long association with visual arts but the processes I want to address are those which respond directly to the text and which seek its depiction, rather than using its reputation or it's content as nominal or generative 
starting points. I also make some distinction here between the illustrative response as commission (editorial illustration or cover design, for instance) and those resulting from a longer-term more open investigation of the text.

'...attempting to clarify something which is slippery and irresolute in its fluid states as performative act and idea; as sign and symbol and signifier: as conceptual diagramme as well as medium and process and technique. With many many uses, manifestations and applications' (Petherbridge, 2008).

Though here commenting on the useful liminality of drawing, Petherbridge could be describing Finnegans Wake itself.

Graphic art has been responding to Finnegans Wake since before its publication as a single volume. Eighteen-year-old Stella Steyn was asked by the author himself to create illustrations in response to the Anna Livia section of Work in Progress. Imagine - your given text is an embryonic chapter of Finnegans Wake and James Joyce is your Art Director! Illustrative visual adaptation of the text has produced a fascinating diversity of worth briefly alluding to here. Those in which I am particularly interested can be divided into the schematic and the pictorial. Lazlo Moholy-Nagy in his pedagogic text Vision in Motion conceives the Joyce's book as a unified spatial entity with circularity and interconnectedness being two characteristics immediately registered by the viewer (Moholy-Nagy 1947). This schematic is not just a legible analysis but a significant graphic representation of the Wake. The image attempts to show the thing itself rather than being an inspired extension of it. Diagrams used in Joyce's Book of the Dark (Bishop 1986) to convey etymological and spatial information also can be read as illustrative visualisations of the text. Bishop's relief maps embed textual quotation and figural outlines in notional topography as visualisations of Bishop's spatial reading of the dreamer. Umberto Eco's synaptic mappings of the single portmanteau word 'meandertale' (p.18.22 in Finnegans Wake) can also be viewed as graphic depictions of the generative surface flow of 'Wakese' (Eco, 1994).

Pictorially Illustrative interpretation of Finnegans Wake that have inform my practice include the work of Tim Ahern, Carl Flint, Heather Ryan Kelly, Stephen Crowe, John Vernon Lord and Thomas McNally. Ahern's pioneering Ilnesstrated Colossick Iditions aim to show as much as to tell. His economically humorous and numerous interpretations offer the double presence of text and image in each page spread. Ahern illustrations follow a long tradition of secularisation in making the Wake accessible through his strategy of entertainment, exploiting the direct communicative potential of 
doodle, cartoon and icon (Ahern 1983 and 2010). Carl Fint's illustrations in the Finnegans Wake section of David Norris's Joyce for Beginners access a similar darker vein of humour to Ahern. Within this publication they necessarily summarise exegetical commentary not direct readings in the original work. Though set with direct quotations they are distanced from the original text to the extent that they are 'applied' to it. Christa-Maria Lerm Hayes points out the ease with which some of Heather Ryan Kelly's work can be misunderstood as 'pinning down' elements of the text in a 'mimetic illustration' (Hayes 2004: 275). In fact her work can be seen as addressing Joyce's interest in using multiple styles. It's precise, systematic arrangement symbols and polysemic potential in images such as Washers at the Ford can be viewed as subverting mimetic illustration, but it is mimetic in its specific use of figuration and, more crucially, in its visual imitation of Wakean ambiguities, slipperiness and encouragement of multiple simultaneous readings. Designer Stephen Crowe's adept illustrations of Finnegans Wake incorporate something of Kelly's stylistic diversity but utilise the Wakean humour illuminated by Ahern. Crowe celebrates Joyce's de-differentiation of 'high' and 'low' cultural inferences and his way of lending profundity to the absurd and vice versa (Crowe, Wake in Progress). John Vernon Lord's illustrations and frontispiece for the Folio Society's Anniversary edition of Finnegans Wake have great affinity for the text and achieve an admirable balance of figurative density, technically accomplishment and stylistic diversity Their textural impact is redolent of immersive entanglement in the Wake, whilst meeting the ambitious qualitative requirements of a fine edition (Lord 2014). Thomas McNally's forty six illustrations to The Ondt and The Gracehoper, deals with 'Part' III, 'Chapter' 1 of Finnegans Wake, a retelling of Aesop's fable. The images are distinctly separated from the text in a storybook format. They are hard-edged and self-contained, their geometric style is tense and cubo-futurist, projecting the essential strangeness of the tale (McNally 2014).

My own fascination with Finnegans Wake began around 1994. I had enjoyed Ulysses immensely but my attempts to read the Wake were a very different experience. Before I got anywhere near being able to 'follow' the text in any sustained way, before it afforded me any pleasure, I found myself wanting to celebrate its mere existence in the world. I was glad that someone had written such an absurdly glorious and extraordinary work, one that that refused to behave like other books. I was drawn to its texture, density and layering long before making any sense of its sentences.

Prior to developing a more methodical way of working my visual responses to the text were sporadic and intuitive depictions of personages, episodes, situations, settings and other aspects of the book as they occurred to me and in no particular sequence. This helped me to realize the immense potential that the text holds for visual artists. But I felt that there was something more interesting going on in 
the way that the language of the Wake made me dwell on how its words were provoking imaginative visual impressions. It seemed that this was made oddly more apparent in the Wake than with other books. So I decided to make a closer, page-by-page reading which might capture some sense of these images as they occurred at the moment of reading, and through these nurture my own understanding of the text.

I approach Finnegans Wake with the view that part of its distinctive difficulty arises from the aforementioned indeterminate condition between word and image. Using a personal, systematic method of annotative reading-drawing, informed by selective contextual reading. I am attempting to investigate and record experiences of reading through notational processes that render visible a core sample of imaginative responses to the text. This process of visualising through reading, imagining and imaging the textual object occurs in several ways outlined below.

Recursive close reading and heavy annotation of a single edition of the text, without concordances or exegeses to hand. I regard annotation as an integral part of the reading act and as the first layer of the reflexive drawing process. I use a 2000 Penguin Classics paperback edition. I have others, but this is the one in which my reading of Finnegans Wake first began to flow (Joyce 1939).

I made page-by-page maps and later 'meta-drawings'. The maps were a diagrammatic approach to apprehending the general shape of the text, the wholeness of the object. I used some of the standard critical exegesis a basis for these, trying to form a kind of consensual sense of what other readers think is going on in the book (Benstock 1976, Burgess 1966, Campbell and Robinson 1944, Hart 1962, Litz 1964, Tindall 1996). I then elaborated this framework with my own thoughts. What I call 'meta-drawing' is an attempt to register the affective relationship between my body, my consciousness and the book as a given object. These arose from contemplating the dynamic relationship between the reader and the book form. They are made from outside the text but at the threshold of entry, using the memory and anticipation stimulated by the physical presence and present of the book, by focusing awareness, within the drawing action, on my previous and future interactions with it. This self-conscious situating of the material and text of Finnegans Wake foregrounds that aspect of the book form which physically and visibly signals what has been and what remains to be encountered, even if this is simply as volume. The diagrammatic character of these experimental drawings is illustrative. They are multiple marks tracing the shifting directions of attention that have advanced my understanding of the body-reading-drawing dynamic. Maps and meta-drawings are made from outside the text, as are related sets of digital prints from accumulated 
annotated text and sketchbook pages, through which I am attempting to reveal something of the exterior textual surface of the Wake.

I handwrite notes in a left hand sketchbook page numbered to correspond with a page in the text. The notes synthesize the annotations in that page. I then re-read the text while making rapid pictorial notations of the mental impressions it provokes. Each double page sketchbook spread shows a direct transition from word idea to picture idea in response to a page of the Wake. Visual impression are recorded in pencil to enable the rendering of fleeting images to be made with sufficient speed and also to exploit the fluid contingency associated with drawing. For expediency written pencil notations are also sometimes added to record complex aspects such as colour, texture, and style references.

I make further developmental drawings from selected passages of text. They are usually larger than the sketchbook drawings and I use other media, such as charcoal, ink and bleach to address ideas concerned with scale, edge, and interiority. These drawings as also made in the moment of reading; i.e. inside the text. Though an anachronistic medium, charcoal is sufficiently responsive, mutable and unstable to be analogous to the way the wake's polysemy holds divergent possibilities in surface play until the reader emphasises a particular meaning or nuance, while retaining the traces of alternatives previously considered. Its range of mark-making possibilities makes it ideal for gathering the 'evidence of many glances' into an unstable accumulation that resists completion in a manner befitting the Wake (Berger 2005). These developmental drawings have introduced a deeper consideration of mimesis to my practice, and consideration of how this relates to reading-drawing at the level of the grapheme. They are made with both the printed, annotated text and the sketchbook notes to hand, but are nevertheless one step removed from the direct reading of the book. Producing these larger drawings has prompted questions of scale (visual field, gesture, notional and material space) reading environments and body posture. It has also been one of ways through which the problems of actively responsive, non-finito 'open' drawing verses departures into interpretive compositional statements (in the context of illustrative mark-making) have been encountered and considered. The drawings escape the constraints of the sketchbook relative to the density of information being included on any given page spread, whilst seeking to retain a page-by-page adaptive correspondence between text and drawing, along with some sense of the bodily relationship between reader and text, the intimacy of reading.

I started to make ink and bleach drawings in direct response to Bishop's analysis of the sensorium of the sleeping consciousness of the Wake and the scopic system that might obtain there, Joyce's 
'oneiratic glow world' (Bishop 1986 pp. 216-63). This is an interior visual system of conjured phosphorescence occurring in a space without edges and un-reliant on the physics of diurnal light. Illustratively charcoal and pencil drawings bring forth images into the light of day but do not really deal with the interiority of the image response, or the nature of the space within which this occurs. Using bleach to 'un-draw' mental images from a dark background is an attempt to investigate and more closely emulate this interiority.

Reviewing digitally sampled passages of drawing to reveals details and nuances of which I am unaware whilst in the midst of the reading-drawing action. What began primarily as a means of documentation and of exploring details led unexpectedly to an interesting and valuable process of capture, re-reading, reviewing and experimental re-composition. When working at speed in to capture fleeting impressions particular configurations of marks or interesting juxtapositions of motif are not always apparent to me. Exiting the text, emerging from the reading-drawing mode and reviewing what has occurred, what has actually been drawn (what graphically remains of the reading) is often surprising. This quality of surprise has become a significant and unexpected pleasure of the method that warrants further investigation.

Reading the Wake through drawing heightens two basic aspects of the medium; its temporal relationship with text in the 'now' of the reading act - drawing sense from literature at the point of encounter; and the trace this leaves of sense taken in that encounter. This state change from performance to index, drawing act to drawing object, process to residue, leads me to the pleasures of 'sampling' or re-reading pictorial notation. Once back 'outside' the text reviewing passages of notation I discover gestural qualities, nodes and clusters of interpretation unnoticed during the act of drawing. Decisions, indecisions, indiscretions are exposed to slow scrutiny (Taylor 2008:10). The non-linear way in which significant nodes and patterns of meaning are accrued when reading the Wake, makes these re-readings particularly useful to my project and a source of frequent surprise.

There is a convention amongst 'Wakeans' of reading aloud in groups, discussing sections of text with the aid of reference material. I want to record visual imaginative responses through a reading practice that can more recognisably be associated with the contemporary consumption of literary works in print; an individuated silent reading and direct engagement with the text as it is given in the published book.

I cannot cast myself as an ordinary reader, whatever that is, or an 'ideal reader' (in Joyce's terms an insomniac). I practice self-conscious reading as part of a process of translation between text and 
image experiences; a process which is at the heart of Illustration. That I have preconceptions, previous experience and critical knowledge of the text can neither be forgotten nor ignored. I cannot be an innocent eye, so any perceived conflict in the method must, at the level of practice, accommodate this reality. Like any reader, I know what I know. Foreknowledge, and the ability to suspend it, is not usually regarded as an obstacle to the reading of literature. This must certainly be the case with a book notionally designed for multiple successive readings. I am fascinated by qualities in my own imaginative responses to the book. As a visual practitioner, it seems natural to explore and record these through drawing. I attempt to do this in a way that is integral to the reading process itself.

What is it that happens when I read and imagine Finnigans Wake?

What is it like in there, in the Wakean universe?

How can I use the images provoked by literature to apprehend literature?

Referring to the 'untenable text, the impossible text', Barthes determined that 'you cannot speak "on" such a text, you can only speak "in" it, in its fashion, enter into a desperate plagiarism, hysterically affirm the void of bliss (and no longer obsessively repeat the letter of pleasure). Bishop reminds us that in the Wake, and in our dreams, there is no light natural light to see by (Bishop 1986). I for one am incapable of finding my way through the shifting densities of Finnegans Wake text without becoming my own Arnie Saccnuson and leaving a sign to show I have passed this way before. My drawing gropes in Derridean blindness between text space and headspace, grasping whatever fleetingly recognisable figurations emerge. Some of us need a line to hold on to.

Marking and re-marking my soft back edition with personal annotation - page-by-page, reading-byreading - gradually applies a graphic skein congruent with the original text. This skein traces my encounters with the Wake at the point of contact - a depiction of my reading.

Marks are basic components of drawing that symbolically relate, and relate to, experience, while not being necessarily similar to anything real (Rowson 1969). The marks and strokes of my notational drawing relate my experiences of reading. They are not, and cannot be, directly mimetic images of what is in my head. They can, however, record in some form what I am internally 'seeing'. To draw is to look and to examine the structure of appearances (Berger 2005) and its practice affirms the equal importance of the conceptual and the perceptual, of interior and exterior vision (Petherbridge 2008). 
Written paper space, a flat, lateral ground for the verbal figure, is transformed by drawing. The virtual character of sketchbook space does not pre-exist drawn marks but becomes defined by their accumulation. Drawing is generative. Marking a surface transforms it, disrupting its neutrality and changing flatness into imaginary space, translating real material reality into fiction. Drawing space is formed chaotically by the visualisation of language. Emergent graphic objects generate contingent meaning. The reading-drawing process exploits the ability in drawing to create notional spaces possessing material and immaterial qualities and in which we can see ideas come into being.

Drawing persists as a fundamental means of recording and analysing the worlds we inhabit (Taylor 2008: 9). If we understand the literary text as an imaginary world created by writing, activated and inhabited through acts of reading, then I advocate drawing as a means of enhancing, documenting and discussing experiences of reading. Drawing has long been a means of reading the world, including our interior worlds, and is still available for the observation and recording of responses of inner vision evoked by language.

Why draw and not write about writing? Drawing is the base pictorial action (Rosand 2002) and is the most direct means to pictorially record my imaginative responses to the Wake. Where writing is conventionally seen as attempting to 'fix' ideas precisely in language, drawing offers the potential for deliberate and constructive vagueness; the incompleteness valued in creative thinking. These characteristically generative, contingent aspects of drawing make it particularly appropriate for the visual interpretation of the Wake, an object text that also resists completion.

\section{Where am I?}

Where is my centre of gravity, the 'whereness' of my reading?

Text space? Paper space? Cyberspace? Some Bachelardian shell space in a sleeping giant's ear or perhaps in Joyce's hypermachinic engine room?

Reading-through-drawing translates text between interior and exterior states, from word to internal perception to readable external representation and so on. When this respirational process is in flow the reading consciousness seems to oscillate between the textual world and the notional space of drawing via the groundless space of imagination. In the now of the dual drawing-reading action the marks that accumulate are only partially apprehended. If, as drawing reader, I become too conscious of formal or representational qualities of the image I falter and fall outside the text, to find myself simply making a drawing. 
The Wake is reluctant, retentive. My notation is a mimetic image, it imitates, it is a kind of copy, is like my experience of reading Finnegans Wake. For me the annotative gesture does more than simply chart progress. My reading coagulates where it is applied. Where it sticks reading is made, leaving traces of my behaviour in and on the text. It says "my reading was like this". And it is transforming my copy of the book (which I do claim as my own) into a palimpsest of Joyce's published words and a representation of my reading of them; an occupation - I occupy the reader's space in the text. The marks I make are of exploration and occupation, they are navigational and territorial. As reader I lay claim to these at least, in all their tentativeness, uncertainty, apprehension and misunderstanding.

My pleasure in Finnegans Wake feels a-social. Of course this can only be in a narrow sense. Reading can be neither totally solitary nor silent. The entanglement of the visual and the audible in the very structures and history of reading and writing disallow the truly silent. Equally intractable is the embedding of the reader in their culture and their time, and the distance of these from the author. The a-social condition is a desired ideal of reading at most, a subjective attitude or pretence. The silent respiration of reading-drawing reinforces attitude. These are my mental impressions even if they are comprised of graphic conventions and shared visual language. I need to re-read my marks to see precisely what I have made because (Barthes again) 'my body pursues its own ideas - for my body does not have the same ideas that I do'. This seems to be in the nature of drawing as much as reading.

Aware of myself as a reading body, I am a doubly perverse reader. An appropriator. I recognize myself authoring a personal configuration of the text, one that is continually changing and embracing its own mutability. I am aware of my past and present experiences of reading this text, of making a visual practice of reading it; of being someone whose own, authored productions derive from reading it. One who knows at last how to take pleasure and seek bliss in imaginings of this text. I have come to value my own version of Finnegans Wake in all its similarity and difference from others.

As a maker, user and reader of drawings, I see meaning in Finnegans Wake as primarily experiential and embodied. It resides in attention to the act of reading and is generated through the perpetual rehearsal of reading. Reading mediated by drawing here is the production not of a fixed statement or summative image, but an ever-churning recombination of the Wakes images with my own. For some the reading experience is overwhelmingly auditory, for me it is a continually unfolding visual image. 
Ahern, T. (1983) James Joyce Finnegans Wake Chapter One: The Illnesstraited Colossick Idition, Seattle and London, University of Washington Press.

Ahern, T. (2010) James Joyce Finnegans Wake The Final Chapter: The Illnesstraited Colossick Idition, Massachusetts: AFIPR

Barthes, R. (1995) The Pleasure of The Text, Oxford: Basil Blackwell Ltd., translated by R. Howard, (1975), originally published as Le Plaisir du texte (1973), Paris: Editions du Seuil.

Berger, J. (2005) 'Drawn to that Moment', in J. Savage (Ed.), Berger on Drawing, Cork: Ireland Occasional Press, 2005. p. 46, in an article which first appeared as 'To Take Paper' in Harper's Magazine (1987), cited in Deana Petherbridge, 'Nailing The Liminal: the Difficulties of Defending Drawing' in S. Garner, 2008, Writing on Drawing, Bristol: Intellect.

Benstock, B. (1976, original 1965) Joyce-Again's Wake: An Analysis of 'Finnegans Wake' Seattle: University of Washington Press.

Bishop, J. (1986) New edition, (1993), Joyce's Book of The Dark, Wisconsin, The University of Wisconsin Press. pp. 32 - 35, 160 - 164.

Bishop, J. (1986) New edition, (1993) ‘ Meoptics’ in Joyce’s Book of The Dark, Wisconsin, The University of Wisconsin Press. pp. 216 - 263.

Burgess, A. (1966) A Shorter Finnegans Wake by James Joyce, London:Faber and Faber Campbell, J., and Robinson, H. (1944, 1961) A Skeleton Key to Finnegans Wake, London: Faber \& Faber.

Crowe, S., 'Wake in Progress', http://www.wakeinprogress.com

Eco, U. (1994) The limits of Interpretation, Bloomington and Indianapolis: Indiana University Press. Flint, C. and Norris, D. (1994) Joyce for Beginners, Cambridge: Icon Books.

Garner, S. (2008) 'Towards a Critical Discourse in Drawing Research' in Writing on Drawing, Bristol: Intellect, p.36.

Hart, C. (1962) Structure and Motif in 'Finnegans Wake', London: Faber \& Faber.

Hayes, C. (Dublin 2004) Joyce in Art: Visual Art inspired by James Joyce, Dublin: Lilliput Press Hayes, C. (Dublin 2004) Joyce in Art: Visual Art inspired by James Joyce, Dublin: Lilliput Press, p.275.

Joyce, J. (1939) Finnegans Wake, Penguin Classics edition reprinted 2000, London: Penguin.

Litz, A. (1964) The Art of James Joyce: Method and design in Ulysses and Finnegans Wake.

Lord, J. V., (2014) illustrations in Joyce, J. Finnegans Wake, London: The folio Society.

McNally, T. (2014) illustrations in Joyce, J. The Ondt and the Gracehoper, Dublin: Lilliput Press.

Moholy-Nagy, L. (1947, Chicago 1961) Vision in Motion, Paul Theobald, p.347 - 50.

Nell, V. (1988) Lost in a Book: The Psychology of Reading for Pleasure, New Haven and London, 
Yale University Press.

Petherbridge, D. (2008) 'Nailing the Liminal: The Difficulties of Defining Drawing' in S. Garner, (ed.) Writing on Drawing: Essays on Drawing Practice and Research, p.32.

Rosand, D. (2002) Drawing Acts: Studies in Graphic Expression, Cambridge: Cambridge University Press, p.1.

Rowson, P. (1969) Drawing (The Appreciation of the Arts, 3) London, New York, Toronto: Oxford University Press, p.1, cited in Cited in D. Petherbridge, Nailing The Liminal: the Difficulties of Defending Drawing in S. Garner (2008) Writing on Drawing, Bristol: Intellect.

Taylor, A. (2008) 'Re-Positioning Drawing' in S. Garner, Writing on Drawing, Bristol: Intellect, p.10. Tindall, W. (1969) A Reader's Guide to 'Finnegans Wake', London: Thames and Hudson. 